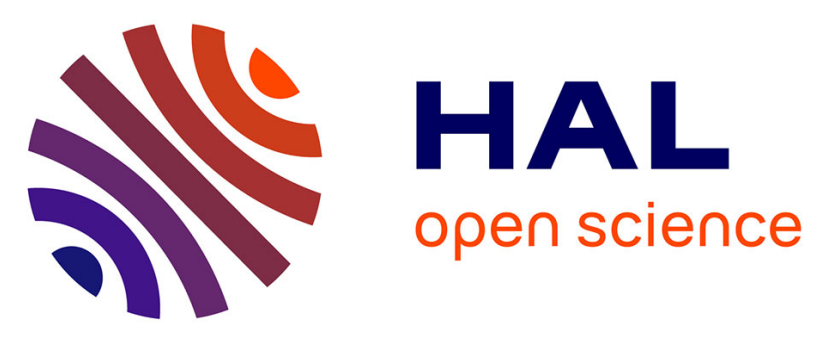

\title{
APOE $\epsilon 4$ and the influence of sex, age, vascular risk factors, and ethnicity on cognitive decline
}

Steve R Makkar, Darren M Lipnicki, John D Crawford, Nicole A Kochan, Erico Castro-Costa, Maria Fernanda Lima-Costa, Breno Satler Diniz, Carol Brayne, Blossom Stephan, Fiona Matthews, et al.

\section{To cite this version:}

Steve R Makkar, Darren M Lipnicki, John D Crawford, Nicole A Kochan, Erico Castro-Costa, et al. APOE $\epsilon 4$ and the influence of sex, age, vascular risk factors, and ethnicity on cognitive decline. Journals of Gerontology Series A: Biological Sciences and Medical Sciences, 2020, 75 (10), pp.18631873. 10.1093/gerona/glaa116 . hal-03380273

\section{HAL Id: hal-03380273 \\ https://hal.inrae.fr/hal-03380273}

Submitted on 15 Oct 2021

HAL is a multi-disciplinary open access archive for the deposit and dissemination of scientific research documents, whether they are published or not. The documents may come from teaching and research institutions in France or abroad, or from public or private research centers.
L'archive ouverte pluridisciplinaire HAL, est destinée au dépôt et à la diffusion de documents scientifiques de niveau recherche, publiés ou non, émanant des établissements d'enseignement et de recherche français ou étrangers, des laboratoires publics ou privés.

\section{다(1)(2)}

Distributed under a Creative Commons Attribution - ShareAlikel 4.0 International 


\section{APOE $\varepsilon 4$ and the Influence of Sex, Age, Vascular Risk Factors, and Ethnicity on Cognitive Decline}

Steve R. Makkar, PhD, ${ }^{1, *}$ Darren M. Lipnicki, PhD, ${ }^{1}$ John D. Crawford, PhD, ${ }^{1}$ Nicole A. Kochan, PhD, ${ }^{1}$ Erico Castro-Costa, MD, PhD, ${ }^{2}$ Maria Fernanda Lima-Costa, MD, PhD, ${ }^{2}$ Breno Satler Diniz, PhD, ${ }^{3,4}$ Carol Brayne, PhD, ${ }^{5}$ Blossom Stephan, PhD, ${ }^{6}$ Fiona Matthews, $\mathrm{PhD},{ }^{6}$ Juan J. Llibre-Rodriguez, MD, PhD, Jorge J. Llibre-Guerra, MD, MSc, ${ }^{8,9}$ Adolfo J. Valhuerdi-Cepero, MD, MSc, ${ }^{10}$ Richard B. Lipton, MD, ${ }^{11}$ Mindy J. Katz, MPH, ${ }^{11}$ Cuiling Wang, PhD, ${ }^{11}$ Karen Ritchie, PhD, ${ }^{12,13}$ Sophie Carles, PhD, ${ }^{14,15}$ Isabelle Carriere, PhD, ${ }^{12,13}$ Nikolaos Scarmeas, MD, PhD, ${ }^{16,17}$ Mary Yannakoulia, PhD, ${ }^{18}$ Mary Kosmidis, PhD, ${ }^{19}$ Linda Lam, MD, ${ }^{20}$ Wai Chi Chan, MD, ${ }^{20}$ Ada Fung, PhD, ${ }^{21}$ Antonio Guaita, MD, ${ }^{22}$ Roberta Vaccaro, MSc, ${ }^{22}$ Annalisa Davin, MSc, ${ }^{22}$ Ki Woong Kim, MD, PhD, ${ }^{23,24}$ Ji Won Han, MD, ${ }^{23}$ Seung Wan Suh, MD, ${ }^{23}$ Steffi G. Riedel-Heller, MD, PhD, ${ }^{25}$ Susanne Roehr, PhD, ${ }^{25}$, Alexander Pabst, PhD, ${ }^{25}$ Mary Ganguli, MD, ${ }^{26}$ Tiffany F. Hughes, PhD, ${ }^{27}$ Beth Snitz, PhD, ${ }^{28}$ Kaarin J. Anstey, PhD, ${ }^{29,30}$ Nicolas Cherbuin, $\mathrm{PhD}^{30}$ Simon Easteal, PhD, ${ }^{31}$ Mary N. Haan, DRPH, ${ }^{32}$ Allison E. Aiello, PhD, ${ }^{33,34}$ Kristina Dang, MPH, ${ }^{32}$ Tze Pin Ng, MD, ${ }^{35}$ Qi Gao, PhD, ${ }^{35}$ Ma Shwe Zin Nyunt, PhD, ${ }^{35}$ Henry Brodaty, MD, DSc, ${ }^{1,36}$ Julian N. Trollor, PhD, ${ }^{1,37}$ Yvonne Leung, PhD ${ }^{38}$ Jessica W. Lo, PhD, ${ }^{1}$ Perminder Sachdev, MD, PhD, ${ }^{1,36}$ for Cohort Studies of Memory in an International Consortium (COSMIC)

'Centre for Healthy Brain Ageing, University of New South Wales, Sydney, Australia. ${ }^{2}$ Instituto René Rachou da Fundaçaõ Oswaldo Cruz, Rio de Janeiro, Brazil. ${ }^{3}$ Department of Psychiatry, Faculty of Medicine University Toronto, Ontario, Canada. ${ }^{4}$ Geriatric Psychiatry Division, Center for Addiction and Mental Health, Toronto, Ontario, Canada. ${ }^{5}$ Department of Public Health and Primary Care, Cambridge University, UK. ${ }^{6}$ Institute of Health and Society, Newcastle University, Newcastle upon Tyne, UK. 'Finlay-Albarrán Faculty of Medical Sciences, Medical University of Havana, Cuba. ${ }^{8}$ Institute of Neurology and Neurosurgery, Havana, Cuba. ${ }^{9}$ Memory and Aging Center, UCSF, San Francisco, California. ${ }^{10}$ Medical University of Matanzas, Matanzas, Cuba. "'Saul R. Korey Department of Neurology, Albert Einstein College of Medicine, Yeshiva University, New York City, New York. ${ }^{12}$ Inserm, U1061 Neuropsychiatry: Epidemiological and Clinical Research, La Colombière Hospital, Montpellier Cedex 5, France. ${ }^{13}$ Université de Montpellier, Montpellier, France. ${ }^{14}$ Inserm, UMR1153 Epidemiology and Biostatistics Sorbonne Paris Cité Center (CRESS), Paris, France. ${ }^{15}$ Paris Descartes University, Paris, France. ${ }^{16} 1$ st Department of Neurology, Aiginition Hospital, National and Kapodistrian University of Athens, Medical School, Athens, Greece. ${ }^{17}$ Taub Institute for Research in Alzheimer's disease and the Aging Brain, Gertrude H Sergievsky Center, Department of Neurology, Columbia University, New York city, New York. ${ }^{18}$ Department of Nutrition and Dietetics (M.Y.), Harokopio University, Athens, Greece. ${ }^{19}$ Laboratory of Cognitive Neuroscience, School of Psychology, Aristotle University of Thessaloniki, Thessaloniki, Greece. ${ }^{20}$ Department of Psychiatry, The Chinese University of Hong Kong. ${ }^{21}$ Department of Applied Social Sciences, The Hong Kong Polytechnic University. ${ }^{22}$ Golgi Cenci Foundation, Abbiategrasso, Italy. ${ }^{23}$ Department of Neuropsychiatry, Seoul National University Bundang Hospital, Seongnam, Korea. ${ }^{24}$ Department of Psychiatry, Seoul National University, College of Medicine, Seoul, Korea. ${ }^{25}$ Institute of Social Medicine, Occupational Health and Public Health (ISAP), Medical Faculty, University of Leipzig, Leipzig, Germany. ${ }^{26}$ Department of Psychiatry, University of Pittsburgh School of Medicine, Pittsburgh, Pennsylvania. ${ }^{27}$ Department of Sociology, Anthropology, and Gerontology, Youngstown State University, Youngstown, Ohio. ${ }^{28}$ Department of Neurology, University of Pittsburgh School of Medicine, Pittsburgh, Pennsylvania. ${ }^{29}$ Neuroscience 
Research Australia, Sydney, Australia. ${ }^{30}$ Centre for Research on Ageing, Health and Wellbeing, College of Health and Medicine, The Australian National University, Canberra, Australia. ${ }^{31}$ John Curtin School of Medical Research, College of Health and Medicine, The Australian National University, Canberra, Australia. ${ }^{32}$ University of California, School of Medicine, Department of Epidemiology and Biostatistics, San Francisco, California. ${ }^{33}$ Department of Epidemiology, Gillings School of Global Public Health, University of North Carolina at Chapel Hill, North Carolina. ${ }^{34}$ Carolina Population Center, Chapel Hill, North Carolina. ${ }^{35}$ Gerontology Research Programme, Department of Psychological Medicine, Yong Loo Lin School of Medicine, National University of Singapore, Singapore. ${ }^{36}$ Dementia Collaborative Research Centre, University of New South Wales Sydney, Sydney, Australia. ${ }^{37}$ Department of Developmental Disability Neuropsychiatry, School of Psychiatry, University of New South Wales, Australia. ${ }^{38}$ School of Psychology, University of Nottingham Malaysia, Semenyih, Malaysia.

*Address correspondence to: Steve R. Makkar, PhD, Centre for Healthy Brain Ageing, School of Psychiatry, University of New South Wales, Randwick, NSW 2031, Australia. E-mail: stevem@unsw.edu.au

Received: August 22, 2019; Editorial Decision Date: April 13, 2020

Decision Editor: David Le Couteur, MBBS, FRACP, PhD

\begin{abstract}
We aimed to examine the relationship between Apolipoprotein E $\varepsilon 4(A P O E * 4)$ carriage on cognitive decline, and whether these associations were moderated by sex, baseline age, ethnicity, and vascular risk factors. Participants were 19,225 individuals aged 54-103 years from 15 longitudinal cohort studies with a mean follow-up duration ranging between 1.2 and 10.7 years. Two-step individual participant data metaanalysis was used to pool results of study-wise analyses predicting memory and general cognitive decline from carriage of one or two APOE*4 alleles, and moderation of these associations by age, sex, vascular risk factors, and ethnicity. Separate pooled estimates were calculated in both men and women who were younger (ie, 62 years) and older (ie, 80 years) at baseline. Results showed that $A P O E * 4$ carriage was related to faster general cognitive decline in women, and faster memory decline in men. A stronger dose-dependent effect was observed in older men, with faster general cognitive and memory decline in those carrying two versus one $A P O E * 4$ allele. Vascular risk factors were related to an increased effect of $A P O E * 4$ on memory decline in younger women, but a weaker effect of $A P O E * 4$ on general cognitive decline in older men. The relationship between $A P O E * 4$ carriage and memory decline was larger in older-aged Asians than Whites. In sum, $A P O E * 4$ is related to cognitive decline in men and women, although these effects are enhanced by age and carriage of two APOE*4 alleles in men, a higher numbers of vascular risk factors during the early stages of late adulthood in women, and Asian ethnicity.
\end{abstract}

Keywords: Cognitive decline, APOE genotype, Epidemiology, Sex, Ethnicity

Carriage of one or two Apolipoprotein E $\varepsilon 4(A P O E * 4)$ alleles predicts prospective cognitive decline in nondemented older adults (1-10), and this effect increases with age (3,11-13). Furthermore, compared to noncarriers, cognitive decline is faster in homozygous versus heterozygous $A P O E^{*} 4$ carriers $(1,6-9)$, implying that the effects of $A P O E * 4$ on cognitive decline are dose-dependent. However, the nature and direction of sex differences in the relationship between $A P O E * 4$ and cognitive decline are still unclear. For example, female $A P O E * 4$ carriers displayed faster cognitive decline than male carriers in some studies $(5,14-17)$, but not all $(17,18)$. Furthermore, in other studies, larger effects of $A P O E * 4$ homozygosity on cognitive dysfunction and decline were seen in men compared to women (15-18). Complicating things further, another study indicated that the effects of $A P O E^{*} 4$ on cognitive decline were larger in women than men, but only between the ages of 70-80 years, implying that sex differences in the influence of $A P O E * 4$ on cognitive decline may be age-dependent (14). Because all $A P O E * 4$ carriers were aggregated in this study, it is uncertain whether the observed age-dependent sex difference applied to both heterozygote and homozygote carriers. Given these mixed findings, the first aim of the present study was to determine if the relationship between $A P O E * 4$ and cognitive decline was larger in women than men, if this difference occurred in both heterozygote and homozygote $A P O E * 4$ carriers, and whether this was specific to certain age ranges.
The effects of vascular risk factors (eg, atherosclerosis, diabetes, stroke) on cognitive decline are enhanced by carriage of $A P O E * 4$ (19-22). Furthermore, age-related working memory deficits are mediated by increases in blood pressure in $A P O E * 4$ carriers, but not in noncarriers (23). This implies that increasing numbers of vascular risk factors strengthen $A P O E * 4$ 's effects on cognitive decline, and that such effects are compounded by increasing age, although this has yet to be formally tested. Hence, the second aim of the present study was to investigate whether increasing numbers of vascular risk factors exacerbated the effects of $A P O E * 4$ on cognitive decline, and if increasing age further exacerbated these effects.

What also remains unclear is whether the effects of $A P O E * 4$ on cognitive decline differ between ethnicities. In a large meta-analysis by Farrer and colleagues (24) the association between $A P O E * 4$ and Alzheimer's disease (AD) was weaker in African Americans and Hispanics, and stronger in Japanese individuals compared to Whites. Another meta-analysis, however, found that AD risk was lower among $A P O E^{*} 4$ carriers from Asia versus North America or Northern Europe (25). Important to note, however, is that the Asian participants pooled in this meta-analysis came from a broad range of Asian countries (including Russia, Iran, and Turkey) besides Japan. Because of this ethnic heterogeneity, it is difficult to draw definitive conclusions regarding ethnic differences in the effects of $A P O E * 4$ on cognitive decline. In light of these mixed findings, the third aim 
of the present study was to determine if the effects of $A P O E * 4$ on cognitive decline, as well sex differences in these effects, differed between individuals of White and Asian ethnicity.

The Cohort Studies of Memory in an International Consortium (COSMIC) is a collaboration of members from around the world who share data from current or previous longitudinal populationbased studies of aging, with the aim of identifying factors that moderate the risk of dementia and cognitive decline (26). In the present study, harmonized data from 15 studies in COSMIC were pooled to examine the association between $A P O E * 4$ and cognitive decline in late adulthood. Based on previous research, we firstly predicted that in both sexes, carriage of one or two APOE*4 alleles would be related to faster cognitive decline, and that this effect would be worsened by older (baseline) age. Further, we predicted that these effects would be larger in women compared to men. Secondly, we predicted a dose-response effect, such that cognitive decline would be faster among carriers of two versus one $A P O E * 4$ alleles, and that this effect would also worsen with older baseline age. We tentatively predicted that this dose-response effect would be larger in men than women, although we anticipated both sexes to display a comparable worsening of this dose-response effect with increasing baseline age. Third, we hypothesized that the effects of $A P O E * 4$ on cognitive decline, and the worsening of these effects with age, would be enhanced by increasing numbers of vascular risk factors. Finally, in light of the mixed evidence with regard to ethnicity, we did not have explicit hypotheses about whether the effects of APOE*4 on cognitive decline would be stronger or weaker in Asian compared to White individuals.

\section{Method}

We collected data sets from independent research studies participating in COSMIC. Studies are eligible to join COSMIC if they are longitudinal and population-based, evaluated cognition or dementia as a major objective, and recruited participants aged 60 years and older (26). This project was approved by the University of New South Wales Human Research Ethics Committee (HC 12446 and HC 17292). All cohorts contributing data to this study had prior ethics approval and all participants provided informed consent prior to participation (see Supplementary Table 1 for study-specific ethics approval details).

\section{Study Selection}

The 15 participating COSMIC studies provided individual participant data as part of a broader research program to investigate risk and protective factors of cognitive aging and dementia (26) (details about each study are provided in Supplementary Table 2). Studies were included in this meta-analysis if the following individual participant data were available at baseline: age, sex, education, number of $A P O E * 4$ alleles, data for four dementia risk factors (ie, hypertension, diabetes, history of cardiovascular disease, history of stroke), score for a test of general cognition (typically the Mini-Mental State Examination; MMSE), and dementia status. Criteria used to diagnose dementia as well as risk factor data available in each study are provided in Supplementary Table 3. In terms of how APOE*4 was measured, for the majority of studies, cell DNA was extracted from blood samples and/or buccal swabs, and the precise APOE*4 genotype, including number of $A P O E * 4$ alleles, was identified using polymerase chain reaction (PCR) amplification followed by restriction fragment length polymorphism analysis. Further details are provided in Supplementary Table 4. Participants without the requisite data, or who had dementia at baseline were excluded from all analyses.

\section{Cognitive Assessment}

Tests evaluating general mental status and verbal memory were the primary outcome measures as these were available in all studies. General cognition was evaluated using the MMSE (27), which was administered in all but three studies. Two studies instead administered either the Modified MMSE (SALSA) or the Community Screening Instrument for Dementia (CHAS), scores for which were converted to MMSE scores using a published co-calibration table (28). EAS administered the Blessed Information Memory Concentration test, and a validated formula was used to convert these scores to MMSE scores (29). For the assessment of memory, we identified a single memory test that was maximally common across cohorts. This was a delayed word list recall test in 10 studies, and the MMSE three-word recall subscore for the remaining four studies which did not administer a specific memory test. The memory test used by each study is shown in Supplementary Table 3. Both the tests of general cognition and memory were administered to participants once per wave.

\section{Statistical Analysis}

\section{Standardization of outcome measures}

Within each study, raw MMSE and memory scores, pooled across all waves, were firstly transformed to have a Gaussian (or normal) distribution, calculated so that the transformed value had the same percentile value as the original value in the original distribution (in SPSS such scores are described simply as normal scores, but are produced under the Rank Cases procedure). Outliers on these transformed scores were then winsorized to values \pm 3 standard deviations (SDs) from the mean scores. These transformed scores were then standardized by converting to $Z$-scores within each study, using estimated means and $S D$ s of baseline scores within each study at common values of age, sex, and education. These common values were the average values at baseline from data pooled across all studies (common values: age $=72.7$ years, education $=9.0$ years, and sex $=0.42$, indicating $42 \%$ males). $S D$ s used for the calculation of these $Z$-scores were the estimated $S D$ s of the residuals (ie, the standard errors $[S E s]$ of the estimates) obtained from the regression models for each study after adjustment for age, sex, and education. The purpose of such standardization was scale participants' scores, within each study, relative to a standard or typical older adult reference. This method of standardizing scores from multiple studies is essentially the same as that described by Griffith and colleagues (30) for obtaining standardized demographically based category-centered scores. However, instead of obtaining $Z$-scores using means and $S D$ s from subsamples having the same restricted ranges of demographic characteristics, we used regression models to calculate estimated means and SDs for specific common values of demographic variables.

\section{Longitudinal analyses}

A two-step individual participant data meta-analysis was conducted to pool results across studies. Weighted generalized estimating equations (GEEs) were used to analyze the relationship between $A P O E^{*} 4$ and cognitive decline, which incorporates inverse probability weighting to reduce bias in effect size estimates associated with attrition that is not completely random $(31,32)$. To obtain inverse probability weightings, logistic regression was used to regress a missing value indicator variable $(1=$ missing, $0=$ not missing $)$ for 
each outcome at each wave on participants' sex, baseline age, years of education, current data collection wave, presence of hypertension and diabetes, and their most recent outcome score. Predicted probabilities from each model were converted to stabilized inverse probability weightings and entered into the GEE analyses as a scale weight (33).

Multivariable GEE models were fit for each outcome measure in each study using an exchangeable correlation structure. The sandwich estimator was used as it ensures unbiased (ie, robust) $S E$ estimates if the correlation structure has been misspecified, especially when sample sizes are large $(31,32)$. The model included $A P O E * 4$ group (carriers vs noncarriers), time in study, sex (treated categorically), age at baseline (centered at the mean of 72 years), all higher-order interactions between these variables, and the following covariates: education (centered at the mean of 9 years), hypertension, diabetes, history of cardiovascular disease, and history of stroke. We refit the above model comparing only homozygotes and heterozygotes to investigate the dose dependence of $A P O E * 4$ on cognitive decline. The main model term was the $A P O E * 4 \times$ time interaction, which tested differences in the rate of cognitive decline between pairs of $A P O E * 4$ groups (carriers vs noncarriers; homozygotes vs heterozygotes). The inclusion of interactions with sex $(A P O E * 4 \times$ time $\times$ sex $)$ and baseline age $(A P O E * 4 \times$ time $\times$ age $)$ enabled us to assess whether the association between $A P O E * 4$ and cognitive decline differed between sexes and was related to baseline age. To explore significant interactions involving baseline age, we estimated effects at two distinct baseline ages: 62 years and 80 years, which were the mean of the bottom and top tertiles for baseline age, and represented "younger" and "older" adults at baseline, respectively (34).

To examine whether vascular risk factors moderated the effects of $A P O E * 4$ on cognitive decline, we computed a vascular risk index (VRISK), which was the sum of the following risk factors: hypertension, diabetes, history of cardiovascular disease, history of stroke, high cholesterol and current smoking (11), each of which coded as being present (1) or absent (0). A VRISK score was computed for participants with data for at least four risk factors. We repeated the above GEE analysis including VRISK (treated as numeric and continuous), $A P O E^{*} 4$, time in study, age at baseline (centered at the mean), sex, and all interactions between these variables, controlling for education. The study-wise GEE analyses were fit in SPSS 23.0 (35). Regression coefficients for model terms were then pooled with random effects meta-analysis using the metan package in Stata 13 (36).

We next examined whether the relationship between $A P O E * 4$ and cognitive decline, and its moderation by age, sex, and vascular risk factor history, differed between groups of White and Asian people. The White group included all individuals that were selfreported or classified as a White person from nine cohorts of predominantly White people (CFAS, EAS, ESPRIT, HELIAD, Invece. Ab, LEILA, MoVIES, PATH, and Sydney MAS), and included in the Asian group were all individuals from three cohorts in countries with majority Asian populations (HK-MAPS, KLOSCAD, and SLASI, with the last cohort comprising 95.6\% Chinese, 1.8\% Malay, $2.1 \%$ Indian, and $0.6 \%$ other). Individuals from the Latin American and North American Hispanic cohorts (Bambui, CHAS, and SALSA) were not included in these groups. Each of the study-wise GEE models described above were refit, and meta-regression was performed on model terms using the Stata metareg package, where ethnicity was treated as a binary, study-level variable (White $=0$, Asian = 1). Significant interactions with ethnicity indicated that the term of interest (eg, APOE*4 $\times$ time) differed between the two ethnoregional groups.
Data availability statement

Data used in this meta-analysis can be made available by request to p.sachdev@unsw.edu.au.

\section{Results}

\section{Participant Characteristics}

Meta-analyses were performed on 19,225 participants spanning 15 studies, after excluding participants with dementia, or those lacking data for age, sex, education, baseline score for a test of general cognition or mental status, and baseline risk factors. Across studies, samples varied in size from 215 to 3,517 participants. As shown in Table 1, the maximum number of assessment waves ranged from 2 to 16 . The median number of assessment waves ranged between 1 and 12 . The mean follow-up time ranged between 1.2 and 10.7 years across studies. Close to half the included studies had more than four assessment waves and a mean follow-up time of more than 5 years. The maximum follow-up duration ranged from 4 to 19.6 years (see Supplementary Table 5).

Baseline demographic characteristics of included participants are shown in Table 1, and baseline proportions of participants having each of the vascular risk factors are displayed in Supplementary Table 6. In all but two studies, women outnumbered men. Mean years of education ranged between 2.8 and 13.8 years, with an overall mean of 9 years. The majority of participants in each study were noncarriers (ranging from $73 \%$ to $86.7 \%$ ). The proportion of participants that were heterozygote $A P O E * 4$ carriers ranged between $11.4 \%$ and $25 \%$, whereas the proportion of participants that were $A P O E * 4$ homozygotes ranged between $0 \%$ and $2.1 \%$. Across studies, the median VRISK score ranged between 1 and 2 risk factors.

\section{Effect of $A P O E^{*} 4$ on Cognitive Decline}

Table 2 displays the main effects of $A P O E * 4$ status, indicating differences in baseline memory and MMSE performance between $A P O E * 4$ carriers versus noncarriers, and between homozygotes and heterozygotes. The main effect of time is displayed capturing the annual change in MMSE and memory scores (ie, cognitive decline) in noncarriers. The APOE*4 $\times$ time interaction is displayed conveying the increment in the annual rate of MMSE and memory decline for $A P O E * 4$ carriers relative to noncarriers, and then in homozygotes relative to heterozygotes. The APOE*4 $\times$ time $\times$ age interaction reflects the amount by which group differences in cognitive decline (ie, between $A P O E * 4$ carriers vs noncarriers, and then between homozygotes vs heterozygotes) increased or decreased per 1-year increase in age at baseline. Finally, the $p$-values for significance tests comparing sex differences on these model terms are displayed. Only model parameters pertinent to cognitive decline are discussed.

\section{Women}

In women overall, $A P O E * 4$ carriers displayed significantly faster cognitive decline compared to noncarriers for the MMSE only ( $B=$ $-0.026, S E=0.008, p=.002)$ as indicated in Figure 1A. Although a dose-dependent $A P O E * 4$ effect is implied by Figure $1 \mathrm{~A}$ and $\mathrm{B}$, this was nonsignificant for both measures. Furthermore, as indicated in Figure $1 \mathrm{~A}$ and $\mathrm{B}$, the effect of $A P O E * 4$ on MMSE or memory decline was not significantly moderated by baseline age. This is reinforced by Figure 1C and D, which shows a comparable effect of $A P O E * 4$ carriage, particularly carriage of two versus one $A P O E * 4$ alleles, on faster MMSE and memory decline in younger and older females, respectively. Analyses within younger- (ie, 62 years) and 
Table 1. Descriptive Statistics of Each Included Study at Baseline

\begin{tabular}{|c|c|c|c|c|c|c|c|c|c|c|c|c|}
\hline & \multirow[b]{3}{*}{$N$} & \multirow{3}{*}{$\begin{array}{l}\begin{array}{l}\text { Number } \\
\text { of Waves }\end{array} \\
\begin{array}{l}\text { Median } \\
\text { (IQR) }\end{array}\end{array}$} & \multirow{3}{*}{$\begin{array}{l}\text { Time } \\
\text { in Study } \\
M(S D)\end{array}$} & \multirow{3}{*}{$\begin{array}{l}\text { Female } \\
\%\end{array}$} & \multirow{3}{*}{$\begin{array}{l}\text { Age, y } \\
M(S D)\end{array}$} & \multirow{3}{*}{$\begin{array}{l}\text { Education, } \\
\mathrm{y} \\
M(S D)\end{array}$} & \multicolumn{3}{|l|}{$\begin{array}{l}\text { Baseline } \\
\text { Cognition } \\
\text { (Z-score) }\end{array}$} & \multicolumn{3}{|c|}{$A P O E * 4$ Group $^{a}$} \\
\hline & & & & & & & MMSE & Memory & VRISK & NC & HET & $\mathrm{HOM}$ \\
\hline & & & & & & & $M(S D)$ & $M(S D)$ & $\begin{array}{l}\text { Median } \\
\text { (IQR) }\end{array}$ & $\%$ & $\%$ & $\%$ \\
\hline Bambui & 1,313 & $12(7-16)$ & $9.7(5.0)$ & 61.5 & $68.7(6.9)$ & $2.8(3)$ & $-1.02(1.2)$ & $-0.01(1)$ & $2(1-2)$ & 74.9 & 23.2 & 1.8 \\
\hline CFAS & 1,957 & $2(2-3)$ & $3.3(4.0)$ & 64.9 & $74.3(6.6)$ & $9.7(1.8)$ & $-0.04(1.1)$ & $-0.01(1.1)$ & $2(1-3)$ & 76.3 & 21.9 & 0 \\
\hline CHAS & 977 & $2(1-2)$ & $5.5(2.2)$ & 60.1 & $74.1(6.6)$ & $9.4(4.7)$ & $-0.25(1.1)$ & $-0.12(1)$ & $1(0-1)$ & 84 & 14.9 & 1.1 \\
\hline EAS & 873 & $4(2-7)$ & $4.4(3.9)$ & 59.7 & $78(5.3)$ & $13.2(3.5)$ & $0.49(1.1)$ & $-0.16(1.1)$ & $1(1-2)$ & 77.3 & 21 & 1.7 \\
\hline ESPRIT & 2,118 & $4(3-4)$ & $5.4(2.8)$ & 58.3 & $73(5.5)$ & $10.3(3.8)$ & $0.08(1.1)$ & $0.01(1)$ & $2(1-2)$ & 80.6 & 18.6 & 0.8 \\
\hline HELIAD & 901 & $1(1-2)$ & $1.2(1.5)$ & 55.1 & $72.9(5.7)$ & $6.6(3.8)$ & $-0.22(1.1)$ & $-0.23(1.1)$ & $2(1-2)$ & 83.2 & 16.1 & 0.7 \\
\hline HK-MAPS & 255 & $3(2-3)$ & $3.7(2.4)$ & 47.6 & $70.6(6.4)$ & $5.5(4.6)$ & $-0.24(1.2)$ & $-0.15(1.1)$ & $1(0-2)$ & 86.7 & 11.4 & 2 \\
\hline Invece. $\mathrm{Ab}$ & 1,210 & $2(2)$ & $1.8(0.8)$ & 53.3 & $72.2(1.3)$ & $6.9(3.3)$ & $-0.16(1.1)$ & $-0.07(1)$ & $1(1-2)$ & 81.9 & 17.8 & 0.3 \\
\hline KLOSCAD & 3,517 & $2(2)$ & $1.7(0.9)$ & 55.5 & $69.1(6.3)$ & $8.5(5.2)$ & $-0.06(1.2)$ & $0.22(1.1)$ & $2(1-2)$ & 75.3 & 24.1 & 0.6 \\
\hline LEILA & 243 & $6(4-6)$ & $7.3(3.0)$ & 79.8 & $80.5(4.2)$ & $11.9(1.8)$ & $0.08(1.1)$ & $0.06(1.1)$ & $1(1-2)$ & 84 & 16 & 0 \\
\hline MoVIES & 215 & $6(5-7)$ & $10.7(2.5)$ & 51.6 & $73.4(5.6)$ & $10.5(2.5)$ & $0.09(1)$ & $-0.1(1.1)$ & $1(1-2)$ & 74.9 & 23.3 & 1.9 \\
\hline PATH & 2,367 & $3(3)$ & $6.7(2.7)$ & 48.4 & $62.5(1.5)$ & $13.8(2.7)$ & $0.9(1)$ & $0.63(1)$ & $1(1-2)$ & 73 & 25 & 2.1 \\
\hline SALSA & 1,538 & $6(4-7)$ & $5.7(3.0)$ & 58.6 & $70.1(6.7)$ & $7.5(5.3)$ & $-0.09(1.2)$ & $0.05(1.2)$ & $2(1-3)$ & 86.7 & 12.5 & 0.7 \\
\hline SLASI & 788 & $2(1-3)$ & $2.0(1.7)$ & 61 & $64.6(6.8)$ & $7(4.5)$ & $0.05(1.2)$ & $0.18(1.1)$ & $1(1-2)$ & 84.1 & 15.2 & 0.6 \\
\hline Sydney MAS & 953 & $4(3-4)$ & $4.7(2.0)$ & 54.6 & $78.7(4.8)$ & $11.6(3.5)$ & $-0.08(1.1)$ & $-0.28(1.1)$ & $2(1-3)$ & 77.3 & 21 & 1.7 \\
\hline
\end{tabular}

Notes: $\mathrm{APOE}^{* 4}$ = Apolipoprotein E ع4; Bambui = Bambui Cohort Study of Aging; CHAS = Cuban Health and Alzheimer Study; EAS = Einstein Aging Study; ESPRIT = Etude Santé Psychologique et Traitement; HELIAD = Hellenic Longitudinal Investigation of Aging and Diet; HET = APOE*4 heterozygote; HK-MAPS $=$ Hong Kong Memory and Ageing Prospective Study; HOM = APOE*4 homozygote; Invece.Ab $=$ Invecchiamento Cerebrale in Abbiategrasso; $\mathrm{IQR}=$ interquartile range; KLOSCAD = Korean Longitudinal Study on Cognitive Aging and Dementia; $M=$ mean; MMSE = Mini-Mental State Examination; MoVIES = Monongahela Valley Independent Elders Survey; NC = APOE $* 4$ noncarrier; PATH $=$ Personality and Total Health Through Life Project; SALSA $=$ Sacramento Area Latino Study on Aging; $S D$ = standard deviation; SGS = Sasaguri Genkimon Study; SLASI = Singapore Longitudinal Ageing Studies; Sydney MAS = Sydney Memory and Ageing Study; VRISK = vascular risk factor index score.

${ }^{2}$ Values in percentages are in relation to the included sample of the study displayed in the column labeled $N$. Percentages may sum to less or more than 100 due to rounding error.

older-aged (ie, 80 years) women revealed no significant effects of $A P O E * 4$ on MMSE (younger: $B=-0.020, S E=0.012, p=.080$; older: $B=-0.016, S E=0.009, p=.061$ ) or memory decline (younger: $B=-0.012, S E=0.011, p=.306$; older: $B=-0.021, S E=0.014$, $p=.150)$. Further, the dose-response effect of $A P O E^{*} 4$ was nonsignificant in both the younger- (MMSE: $B=0.034, S E=0.114$, $p=.769$; memory: $B=-0.024, S E=0.045, p=0.597)$ and olderaged women for both measures (MMSE: $B=0.137, S E=0.100, p=$ .173 ; memory: $B=-0.084, S E=0.045, p=.064)$.

\section{Men}

Figure $2 \mathrm{~A}$ and $\mathrm{B}$ indicate a strong dose-dependent effect of $A P O E * 4$ on memory and MMSE decline in men, particularly among older-aged males. In men overall, $A P O E * 4$ carriers aggregated together had a significantly faster rate of memory decline than noncarriers $(B=-0.018$, $S E=0.007, p=.013)$. This effect was dose-dependent $(B=-0.062$, $S E=0.029, p=.032)$, implying that the overall effect of $A P O E * 4$ in men was driven primarily by faster memory decline among the homozygotes. There were no significant interactions with baseline age, although results revealed that in older-aged men $A P O E * 4$ carriage predicted faster memory $(B=-0.040, S E=0.015, p=.007)$ and MMSE decline $(B=-0.030, S E=0.015, p=.039)$, but not in younger-aged men (memory: $B=-0.001, S E=0.011, p=.980$; MMSE: $B=-0.008$, $S E=0.008, p=.341)$. Furthermore, a significant dose-response effect emerged in older-aged men for both measures (memory: $B=-0.181$, $S E=0.059, p=.002$; MMSE: $B=-0.179, S E=0.070, p=.011)$, but did not emerge in younger-aged men on either measure (memory: $B$
$=-0.028, S E=0.047, p=.553 ;$ MMSE: $B=-0.066, S E=0.080, p$ $=.412$ ). The fitted trajectories in Figure $2 \mathrm{C}$ and $\mathrm{D}$ show faster rates of decline among older versus younger $A P O E * 4$ carriers, especially the homozygotes. Older baseline age worsened the dose-dependent effects of $A P O E * 4$ on MMSE decline in men more than women $(B=$ $-0.020, S E=0.006, p=.002$ ). Furthermore, the dose-dependent effect of $A P O E * 4$ on MMSE decline in older-aged participants was significantly larger in men than women $(B=-0.226, S E=0.106, p=.034)$.

\section{Interaction Between $A P O E^{*} 4$ Carriage and Vascular Risk Factors}

As shown in Supplementary Table 7, a higher number of vascular risk factors was associated with a stronger $A P O E * 4$ effect on memory decline in younger-aged women $(B=-0.017, S E=0.006$, $p=.007)$. In contrast, a higher number of vascular risk factors was related to a weaker $A P O E * 4$ effect MMSE decline in older men $(B$ $=0.040, S E=0.017, p=.020)$.

\section{Ethnoregional Differences}

Complete results regarding ethnoregional differences in the association between $A P O E * 4$ and cognitive decline are displayed in Supplementary Table 8. Baseline age worsened the effects of $A P O E * 4$ on memory decline in Asians $(B=-0.011, S E=0.005$, $p=.043)$, but not Whites $(B=0.002, S E=0.002, p=.480)$, and this ethnic difference was significant $(B=0.013, S E=0.005, p=$ .037). Furthermore, as illustrated in Figure 3, in older-aged participants, $A P O E * 4$ carriage had a stronger effect on memory decline in 
Table 2. Results of IPD Meta-Analysis Examining the Association Between $A P O E^{*} 4$ and Cognitive Decline

\begin{tabular}{|c|c|c|c|c|c|}
\hline & \multicolumn{2}{|l|}{ Female ${ }^{\mathrm{a}}$} & \multicolumn{2}{|l|}{ Male $^{\mathrm{a}}$} & \multirow[b]{2}{*}{$p$ for sex differences } \\
\hline & $B$ & $\mathrm{CI}$ & $B$ & $\mathrm{CI}$ & \\
\hline \multicolumn{6}{|l|}{ MMSE } \\
\hline \multicolumn{6}{|l|}{$A P O 4^{*} 4^{\mathrm{b}}$} \\
\hline Carrier vs noncarrier ${ }^{d}$ & 0.013 & $(-0.07,0.096)$ & -0.012 & $(-0.108,0.084)$ & $0.660^{\mathrm{h}}$ \\
\hline Homozygotes vs heterozygotes ${ }^{e}$ & 0.003 & $(-0.340,0.3453)$ & 0.077 & $(-0.457,0.61)$ & $0.329^{\mathrm{h}}$ \\
\hline Time $^{\mathrm{c}}$ & -0.021 & $(-0.06,0.018)$ & -0.031 & $(-0.06,-0.002)^{*}$ & $0.021^{\mathrm{i}}$ \\
\hline \multicolumn{6}{|l|}{$A P O E * 4 \times$ time } \\
\hline Carrier vs noncarrier $^{\mathrm{d}}$ & -0.026 & $(-0.042,-0.01)^{* *}$ & -0.014 & $(-0.033,0.005)$ & $0.74^{i}$ \\
\hline Homozygotes vs heterozygotes ${ }^{\mathrm{e}}$ & 0.088 & $(-0.071,0.246)$ & -0.078 & $(-0.171,0.014)$ & $0.709^{i}$ \\
\hline \multicolumn{6}{|l|}{$A P O E * 4 \times$ time $\mathrm{x}$ age $\mathrm{f}^{\mathrm{f}}$} \\
\hline Carrier vs noncarrier & 0.0005 & $(-0.002,0.003)$ & -0.001 & $(-0.003,0.001)$ & $0.238^{\mathrm{k}}$ \\
\hline Homozygotes vs heterozygotes & 0.006 & $(-0.004,0.017)$ & 0.02 & $(-0.009,0.05)$ & $0.259^{\mathrm{k}}$ \\
\hline \multicolumn{6}{|l|}{ Memory } \\
\hline \multicolumn{6}{|l|}{$A P O E^{*} 4^{b}$} \\
\hline Carrier vs noncarrier $^{\mathrm{d}}$ & -0.078 & $(-0.145,-0.011)^{*}$ & -0.063 & $(-0.126,-0.001)^{*}$ & $0.885^{\mathrm{h}}$ \\
\hline Homozygotes vs heterozygotes ${ }^{e}$ & -0.351 & $(-0.676,-0.026)^{*}$ & -0.003 & $(-0.316,0.311)$ & $0.488^{\mathrm{h}}$ \\
\hline Time $^{c}$ & -0.044 & $(-0.078,-0.009) *$ & -0.028 & $(-0.06,0.004)$ & $0.812^{\mathrm{i}}$ \\
\hline \multicolumn{6}{|l|}{$A P O E * 4 \times$ time } \\
\hline Carrier vs noncarrier ${ }^{d}$ & -0.014 & $(-0.03,0.002)$ & -0.018 & $(-0.033,-0.004)^{*}$ & $0.374 i$ \\
\hline Homozygotes vs heterozygotes ${ }^{\mathrm{e}}$ & -0.043 & $(-0.106,0.02)$ & -0.062 & $(-0.119,-0.005)^{*}$ & $0.356^{i}$ \\
\hline \multicolumn{6}{|l|}{$A P O E * 4 \times$ time $\times$ age $^{f}$} \\
\hline Carrier vs noncarrier & -0.078 & $(-0.145,-0.011)^{*}$ & -0.063 & $(-0.126,-0.001)^{*}$ & $0.848^{\mathrm{k}}$ \\
\hline Homozygotes vs heterozygotes & -0.044 & $(-0.078,-0.009) *$ & -0.028 & $(-0.06,0.004)$ & $0.002^{\mathrm{k}}$ \\
\hline
\end{tabular}

Notes: $A P O E * 4=$ Apolipoprotein E $\varepsilon 4$; MMSE $=$ Mini Mental State Examination.

avalues come from multivariate generalized estimating equation (GEE) models including the following terms APOE group, time in study, age at baseline (centered at the mean baseline age of 72), sex, all interactions among these variables, and the following covariates: education (centred at the mean of 9 years), hypertension, diabetes, history of cardiovascular disease, and history of stroke. Terms relating to the effect of APOE*4 on baseline cognition are not discussed.

${ }^{b}$ Values reflect the mean difference in baseline scores, firstly for $A P O E^{*} 4$ carriers versus noncarriers, and then for homozygotes versus heterozygotes on the specified outcome measure. Negative values indicate lower mean baseline scores for carriers relative to noncarriers, or lower mean baseline scores for homozygotes versus heterozygotes.

${ }^{c}$ Values reflect the annual rate of decline in noncarriers on the specified outcome measure, where negative values indicate the average rate of decrease in cognitive scores per year.

${ }^{d}$ Values reflect $B$-coefficients for the $A P O E * 4$ group x time interaction term comparing noncarriers to carriers. Negative $B$-values indicate a faster rate of cognitive decline on the specified outcome measure in $A P O E * 4$ carriers, or in homozygotes compared to heterozygotes.

'Values reflect $B$-coefficients for the $A P O E * 4$ group x time interaction term comparing homozygotes to heterozygotes. Negative $B$-values indicate a faster rate of cognitive decline on the specified outcome measure in homozygotes compared to heterozygotes. These estimates were obtained from a refitted multivariable GEE model where the comparison between carriers and noncarriers was replaced with the comparison between heterozygotes and homozygotes.

fValues reflect $B$-coefficients for the $A P O{ }^{*} 4$ group x time $\mathrm{x}$ baseline age interaction term, with age entered at the mean baseline age of 72 years. Negative $B$ values for the effect of age indicate that if $A P O E * 4$ carriage (or carriage of two vs one APOE*4 alleles) is related to faster decline, this rate of decline increases with every 1 -year increase in age at baseline.

sValues reflect the $p$-values from significance tests of terms comparing the size of the specified model term between men and women, that is, terms involving interactions with sex.

${ }^{\text {h}} p$-value from the significance test of the $A P O E^{*} 4 \mathrm{x}$ sex term, comparing differences between men and women in the effect of $A P O E^{*} 4$ carriage (or carriage of two versus one $A P O E^{*} 4$ alleles) on cognition at baseline.

i $p$-value from the significance test of the $A P O E^{*} 4 \mathrm{x}$ time term, comparing differences between men and women in rate of cognitive decline, per year, among noncarriers.

ip-value from the significance test of the $A P O E * 4 \mathrm{x}$ time $\mathrm{x}$ sex term, comparing the difference between men and women in the effect of $A P O E * 4$ carriage on cognitive decline (firstly between $A P O E * 4$ carriers vs noncarriers, then between homozygotes vs heterozygotes).

${ }^{k} p$-value from the significance test of the APOE" $4 \mathrm{x}$ time $\mathrm{x}$ baseline age $\mathrm{x}$ sex term, comparing the difference between men and women in the effect of older baseline age on $A P O E * 4$-related cognitive decline (firstly between $A P O E^{*} 4$ carriers vs noncarriers, then between homozygotes vs heterozygotes).

* $p<.05, * * p<.01$.

Asians than Whites $(B=0.127, S E=0.046, p=.023)$, and this effect was significant in Asians $(B=-0.136, S E=0.042, p=.010)$ but not Whites $(B=-0.009, S E=0.019, p=.649)$. Subsequent analyses indicated that increasing numbers of vascular risk factors attenuated the effects of $A P O E * 4$ on MMSE decline in Asians $(B=0.085$, $S E=0.027, p=.010)$, but not Whites $(B=0.013, S E=0.014, p=$ $.388)$, and this ethnic group difference was significant $(B=-0.072$, $S E=0.031, p=.040)$.

\section{Discussion}

There was, overall, mixed support for our hypotheses, and we address each hypothesis in turn. Firstly, we predicted that overall, carriage of at least one $A P O E * 4$ allele would be related to faster cognitive decline in both sexes, that these effects would be dependent on age, but emerge as being larger in women compared to men. Partially supporting this hypothesis, we found that $A P O E * 4$ carriage was related 

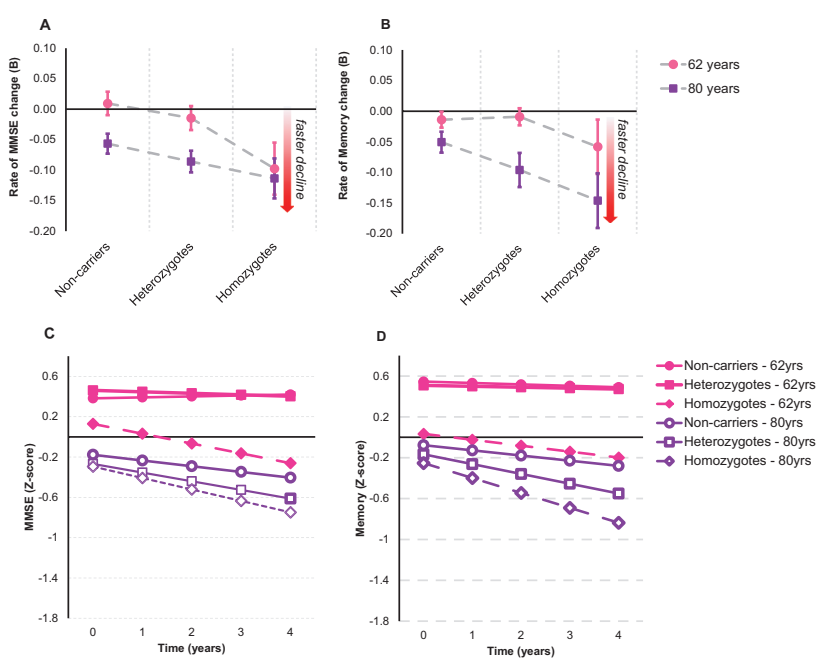

Figure 1. Association between Apolipoprotein $E \& 4\left(A P O E^{*} 4\right)$ and cognitive decline in women. (A) Mean annual rates of change in Mini-Mental State Examination (MMSE) performance and standard errors for women aged 62 years (younger) and 80 years (older) at baseline in each of the $A P O E^{*} 4$ groups. (B) Mean annual rates of change in memory performance and standard errors for women aged 62 years (younger) and 80 years (older) at baseline in each of the $A P O E^{*} 4$ groups. (C) Fitted trajectories plotting changes in MMSE performance over time in 62-year-old (younger) and 80 -year-old (older) women in each of the $A P O E^{*} 4$ groups. (D) Fitted trajectories plotting changes in memory performance over time in 62-year-old (younger) and 80 -year-old (older) women in each of the $A P O E^{*} 4$ groups.

to faster general cognitive decline in women, and faster memory decline in men-although in both sexes, particularly in men, this effect was primarily driven by carriage of two versus one $A P O E * 4$ alleles. These findings broadly align with the body of research indicating that carriage of $A P O E * 4$ predicts prospective cognitive decline (1$10)$. In contrast to our hypotheses, however, the effects of $A P O E * 4$ carriage were not moderated by age at baseline in either sex. We did find, however, that in men but not women, $A P O E * 4$ carriage was related to faster decline of general cognition and memory among those in the older age range, although sex differences at this (or any other) age range did not emerge as significant. In general, prior cohort studies have reported mixed results in relation to whether the effects of $A P O E * 4$ carriage on cognitive decline are larger in women than men. Our analysis, utilizing a large and heterogeneous sample, however, suggests that carriage of $A P O E * 4$ is related to cognitive decline to a comparable degree in both sexes.

Second, we hypothesized that the effects of $A P O E^{*} 4$ on $\operatorname{cog}$ nitive decline would be dose-dependent and to a greater degree in men than women. We also predicted that this dose-dependent effect would increase with older baseline age, and comparably so in both sexes. Partially in line with this hypothesis, we found that carriage of two versus one $A P O E * 4$ allele was associated with faster general cognitive and memory decline in men only, and specifically among those older in age (ie, 80 years). Contrary to our predictions, however, we found that these dose-dependent $A P O E * 4$ effects on decline of general cognition worsened with age in men more than women. Thus, our findings imply that the dose-dependent effects of APOE*4 on cognitive decline, and the worsening of these effects with age, are stronger in men than women.
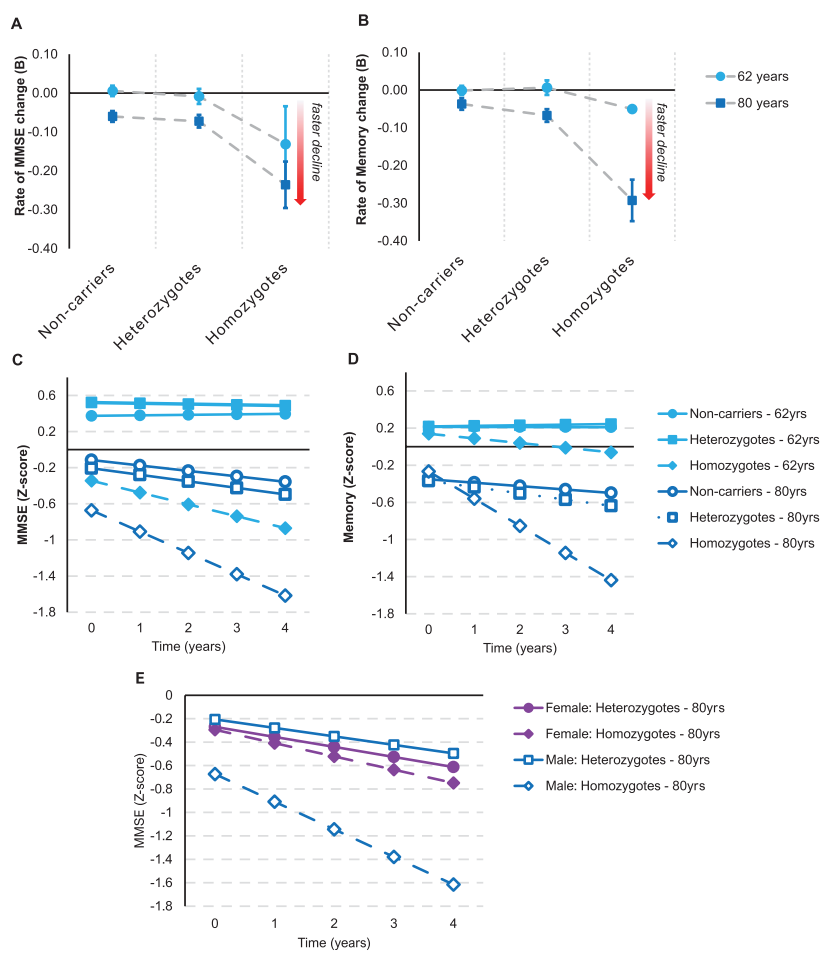

$\rightarrow$ Female: Heterozygotes - 80yrs $\rightarrow$ Female: Homozygotes - 80yrs $\rightarrow-$ Male: Heterozygotes - 80yrs $\rightarrow$ Male: Homozygotes - 80yrs decline in men. (A) Mean annual rates of change in Mini-Mental State Examination (MMSE) performance and standard errors for men aged 62 years (younger) and 80 years (older) at baseline in each of the $A P O E^{*} 4$ groups. (B) Mean annual rates of change in memory performance and standard errors for men aged 62 years (younger) and 80 years (older) at baseline in each of the $A P O E^{*} 4$ groups. (C) Fitted trajectories plotting changes in MMSE performance over time in 62-year-old (younger) and 80-year-old (older) males in each of the $A P O E^{*} 4$ groups. (D) Fitted trajectories plotting changes in memory performance over time in 62-year-old (younger) and 80 -year-old (older) males in each of the APOE* groups. (E) Fitted trajectories plotting changes in MMSE scores in 80-year-old (older) male and female heterozygotes and homozygotes.

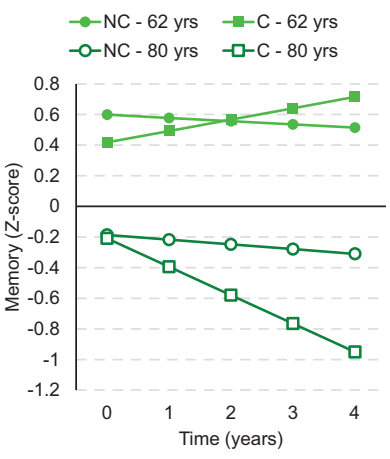

B

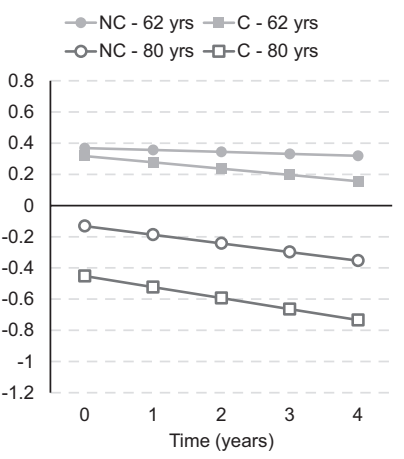

Figure 3. Effects of Apolipoprotein E $\varepsilon 4\left(A P O E^{*} 4\right)$ on cognitive decline in Asian and White men. (A) Fitted trajectories plotting changes in memory performance over time in 62-year-old (younger) and 80-year-old (older) Asian $A P O E^{*} 4$ carriers and noncarriers. (B) Fitted trajectories plotting changes in memory performance over time in 62-year-old (younger) and 80-year-old (older) White $A P O E^{*} 4$ carriers and noncarriers. $\mathrm{C}=$ carrier; $\mathrm{NC}=$ noncarrier. 
Studies have generally reported mixed findings as to whether the effects of $A P O E^{*} 4$ on cognitive decline do in fact worsen with age $(3,11,37-39)$. These mixed results may be partially attributable to studies either pooling sexes and/or heterozygote and homozygote carriers together. Furthermore, whether such age-dependent effects of $A P O E^{*} 4$ on cognitive decline differ between sexes has for the most part not been tested in previous studies. By analyzing sex, baseline age, and number of $A P O E * 4$ alleles as separate variables in the present study, our study was able to provide clarity regarding the complex interaction between $A P O E * 4$, sex, and age. Specifically, our findings suggest that the age-dependent effects of $A P O E * 4$ on $\operatorname{cog}$ nitive decline, specifically its dose-dependent effects, may be larger in men than women. This is in line with studies finding a stronger effect of $A P O E * 4$ homozygosity on cognitive decline in men compared to women in the older age range (ie, above 70 years of age). For example, Lehmann and colleagues (15) found that homozygous men, but not women with a mean age of 73 years were at greater risk of cognitive impairment relative to noncarriers. Similarly, Swan and colleagues found a stronger effect of $A P O E * 4$ carriage on memory decline in men compared to women, whose mean ages were 75 and 71 years, respectively (18). Mortensen and colleagues (14) in contrast, observed a stronger effect of $A P O E * 4$ carriage on cognitive decline in women than men, specifically between the ages of 70 and 80 years. These findings, which are contrary to ours, imply that the effects of $A P O E * 4$ on cognitive decline are exacerbated by age to a greater degree in women than men. However, it should be noted that Mortensen and colleagues (14) administered tests that evaluated executive functions and processing speed. This suggests that $A P O E * 4$-mediated cognitive decline may indeed worsen with age to a greater extent in women than men, but in relation to executive functions and processing speed abilities specifically. In line with these results, Reinvang and colleagues (16) found that $A P O E^{*} 4$ homozygosity was associated with impaired working memory performance in men and not women with a mean age of 65 years, suggesting that the decline of executive abilities occurs earlier in men than women.

Taken together, sex differences in the effects of APOE*4 on cognitive decline, and how these effects are exacerbated by older age may also be dependent on the cognitive ability being evaluated. Our findings suggest that in relation to verbal memory specifically (ie, the cognitive ability measured by the MMSE and memory tests administered in the present study (40)), there is a larger age-related worsening of cognitive decline associated with carriage of two versus one $A P O E * 4$ allele in men than women. Evidence indicates that women have a lifelong advantage over men with regard to verbal memory abilities (41), with more advanced neuropathology needed to detect significant verbal memory deficits in women compared to men. Because of this lifelong advantage, male APOE*4 carriers may evidence larger verbal memory decline with increasing age than female carriers, as indicated by our findings. The mechanisms underlying this gender difference are unclear. Studies indicate smaller hippocampal volume in $A P O E * 4$ homozygous men than women, suggesting that male $A P O E * 4$ carriers may experience more rapid age-related hippocampal atrophy, leading to faster verbal memory decline than women (20). Furthermore, given that testosterone has neuroprotective effects (eg, reduction of $\mathrm{A} \beta$ secretions in cell cultures and phosphorylation of tau proteins (17)), decreasing levels of testosterone in the aging male may progressively worsen $A P O E * 4$-related neurodegeneration over time (20), leading to $A P O E * 4$-mediated verbal memory decline that worsens with age to a greater extent in men than women. Further research is needed to pinpoint the precise mechanisms underlying the stronger age-dependent effects of $A P O E * 4$ on verbal memory decline in men versus women.

For our third hypothesis, we predicted that the relationship between $A P O E * 4$ and cognitive decline would be compounded by increasing numbers of vascular risk factors. We found partial support for this hypothesis, as our results indicated the combined effects of $A P O E * 4$ and vascular history on cognitive decline were moderated by sex and baseline age. Specifically, increasing numbers of vascular risk factors were related to a stronger $A P O E * 4$ effect on memory decline in younger-aged women only. It is known that $A P O E * 4$ and vascular risk factors combine synergistically to induce neurovascular damage and adverse white matter changes that lead to a compounded risk of cognitive decline and AD (19-21,23,42). The fact that significant results were limited to younger women could be because men and women at this age range differed in the extent to which their vascular risk factors were treated (43) or in the combination of risk factors that contributed to their VRISK scores. Results in Supplementary Table 9, however, indicate that a similar proportion of the younger men and women with VRISK scores above 3 had each of the risk factors. Alternatively, our results may indicate a survival bias, given that men do not live as long as women with heart disease (44). Furthermore, among men, APOE*4 carriage has been found to predict death associated with coronary heart disease and stroke $(45,46)$. A survival bias would leave resilient male participants whose cognition would be relatively unimpaired by their vascular risk factor profile irrespective of whether or not they were $A P O E * 4$ carriers. Hence, this may explain why vascular risk factors did not moderate the effects of $A P O E * 4$ on cognitive decline in the younger-aged men.

Interestingly, we found that higher vascular risk factors were related to an attenuated APOE*4 effect on general cognitive decline in older participants, with the effect being significant in older men. This aligns with numerous other studies showing that vascular risk factors (eg, obesity, hypertension, high cholesterol) in later life are related to reduced dementia risk (47-49). These results are again consistent with a survival bias mechanism, as $A P O E * 4$ carriers (particularly males $(45,46)$ ) with multiple vascular risk factors would have likely passed away before 80 (the older age point in our study). Presumably then, the surviving male $A P O E * 4$ carriers at the older age ranges (ie, $80+$ ) would be even more resilient and cognitively intact than those in the younger age ranges (ie, 60+)-hence leading to an attenuated interaction between $A P O E * 4$ and vascular risk factors on cognitive decline among men in the old age range only.

The third and final aim of the present study was to clarify whether there were ethnic differences in the effects of $A P O E * 4$ on cognitive decline. Because the results of previous studies were mixed, we did not have explicit hypotheses regarding whether the effects of $A P O E^{*} 4$ on cognitive decline would be stronger or weaker in Asian compared to White individuals. Our results implied the existence of ethnic differences but at specific ages. Specifically, in olderaged participants, $A P O E * 4$ had a stronger effect on memory decline in Asians versus Whites. Similarly, Farrer and colleagues (24) found that $\mathrm{AD}$ risk was elevated in Japanese versus White $A P O E^{*} 4$ carriers. Crean and colleagues (25), however, found that Asian $A P O E * 4$ carriers had a lower risk of $\mathrm{AD}$ than $A P O E * 4$ carriers from North America or Northern Europe, although the Asian group in this study was quite heterogeneous, as it included participants from countries not typically classified as Asian (eg, Russia, Iran). The ethnic differences we observed are unlikely due to higher vascular risk burden in Asians than Whites given that vascular risk factors did not moderate the effect of $A P O E * 4$ on memory decline in either ethnicity; and increasing number of vascular risk factors weakened the effect of 
$A P O E * 4$ on MMSE decline in Asians and not Whites. Importantly, though, we did not have data on midlife vascular risk factors which are known to be related to more severe cognitive deficits than in late life (50). It is possible that Asians-who are more susceptible to midlife vascular risk factors at "normal” BMI values than White $(51,52)$, displayed faster memory decline because of more extensive neuropathology caused by interactions between $A P O E^{*} 4$ and vascular risk factors experienced in midlife $(47,53)$. The veracity of this explanation cannot be deduced from our study; thus, further research examining the mechanisms mediating ethnoregional differences in vulnerability to $A P O E * 4$ is needed.

\section{Strengths and Limitations}

Strengths of our study include the large sample size and availability of individual participant data, enabling us to explore the influence of age, sex, ethnicity, and vascular risk factors on both the overall and dose-dependent effects of $A P O E * 4$ on cognitive decline. We also controlled for numerous $\mathrm{AD}$ risk factors which has not been performed consistently in previous meta-analyses, strengthening the internal validity of our conclusions. Furthermore, pooling data from 15 population-based studies from 11 countries spread across five continents enhance our ability to generalize findings across non-White populations. In terms of limitations, data were limited to the number of $A P O E * 4$ alleles participants carried as opposed to their entire APOE genotype. Hence, comparisons could not be made between individuals with specific pairs of APOE alleles. Second, data limitations also precluded us from examining whether the contrasting effects of vascular risk factors we observed in younger versus older $A P O E * 4$ carriers were due to differential treatment of vascular risk factors between these age groups. Third, ethnoregional comparisons were limited to Whites and Asians due to the smaller number of participants in other ethnic groups. Finally, only decline on tests of memory and the MMSE was examined (both of which are highly verbal measures), precluding us from generalizing our conclusions to other cognitive domains.

\section{Conclusions}

Although there is overwhelming evidence that carriage of $A P O E * 4$ is related to faster cognitive decline in late adulthood, there is less clarity regarding how this relationship is moderated by age, sex, ethnicity, and the presence of vascular risk factors. Utilizing pooled data from 15 international longitudinal cohort studies, we were equipped with sufficient power to address these moderating factors, and given the diversity of the pooled studies, our results have the potential to generalize to a global scale. Overall, our results indicated a complex interaction between number of $A P O E * 4$ alleles, age at baseline, sex, ethnicity, and current vascular history on the relationship between $A P O E * 4$ and cognitive decline in old age. Namely, we found that $A P O E * 4$ carriage was related to faster decline of general cognitive abilities in women, and faster memory decline in men. Older baseline age worsened the dose-dependent effect of $A P O E * 4$ on general cognitive decline to a stronger degree in men than women. This dose-response effect only emerged in older-aged men. Vascular risk factors worsened the effects the $A P O E * 4$ on cognitive decline in younger women, but attenuated effects of $A P O E * 4$ on cognitive decline in older men. Finally, $A P O E * 4$ carriage was more detrimental to memory decline in older-aged Asians than Whites. Data limitations prevent us from being able to generalize these conclusions across all cognitive domains, $A P O{ }^{*} 4$ genotypes, and to vascular risk factors experienced in midlife, and so these remain fruitful areas for future investigations. Treatment of vascular risk factors, alone, or in combination with preventive care (eg, diet, exercise, intellectual and social stimulation), and APOE-targeted pharmacological interventions could be initiated early to minimize or prevent cognitive decline associated with carriage of $A P O E * 4$.

\section{Supplementary Material}

Supplementary data are available at The Journals of Gerontology, Series A: Biological Sciences and Medical Sciences online.

\section{Acknowledgments}

Acknowledgments and list of members of The Sydney COSMIC team are available as supplementary material.

\section{Funding}

This work was supported by a National Health and Medical Research Council of Australia Program Grant (grant number ID 1093083); the National Institute on Aging of the National Institutes of Health under grant number RF1AG057531; and philanthropic contributions to the Dementia Momentum Fund (University of New South Wales Project ID PS38235), which collectively fund the COSMIC consortium. The content of this publication is solely the responsibility of the authors and does not necessarily represent the official views of the National Institutes of Health or other funders. Funding for the contributing studies is as follows: Bambui: the Brazilian Ministry of Health (Department of Science and Technology); the Brazilian Ministry of Science and Technology (National Fund for Scientific and Technological Development, Funding of Studies, Brazilian National Research Council); and the Minas Gerais State Research Foundation; CFAS: major awards from the Medical Research Council and the Department of Health, UK; CHAS: the Wellcome Trust Foundation (grant numbers GR066133 and GR08002); and the Cuban Ministry of Public Health; EAS: supported in part by National Institutes of Health (grant number NIA 2 P01 AG03949); the Leonard and Sylvia Marx Foundation; and the Czap Foundation; ESPRIT: Novartis; HELIAD: the Alzheimer's Association (grant number IIRG-09133014); ESPA-EU program Excellence Grant (ARISTEIA, grant number 189 10276/8/9/2011), which is co-funded by the European Social Fund and Greek National resources; and the Ministry for Health and Social Solidarity (Greece, grant number $\Delta$ Y2ß/otk.51657/14.4.2009); HK-MAPS: the Mei Family Trust; Invece.Ab: financed with own funds; and supported in part by "Federazione Alzheimer Italia," Milan, Italy; KLOSCAD: the Korean Health Technology R\&D Project, Ministry of Health and Welfare, Republic of Korea (grant no. HI09C1379 (A092077)); LEILA75+: the Interdisciplinary Centre for Clinical Research at the University of Leipzig (Interdisziplinäres Zentrum für Klinische Forschung/ IZKF; grant number 01KS9504); MoVIES: National Institute on Aging, National Institutes of Health, United States Department of Health and Human Services (grant number R01AG07562); PATH: National Health and Medical Research Council of Australia (grant numbers 973302, 179805, 157125, and 1002160); SALSA: National Institutes of Health (grant numbers AG12975, T32 AG049663, ES023451); Carolina Population Center (CPC) grant (the P2C Center grant from the National Institutes of Health, grant number P2C HD050924); CPC NICHD-NRSA Population Research Training (the T32 Training grant from the National Institutes of Health, grant number T32 HD007168); and a Biosocial Training Grant (grant number T32 HD091058); SLASI: Agency for Science Technology and Research (A*STAR) Biomedical Research Council (BMRC) (grant numbers 03/1/21/17/214 and 08/1/21/19/567); and the National Medical Research Council (grant number NMRC/1108/2007); Sydney MAS: National Health \& Medical Research Council of Australia Program Grant (grant number ID 350833). 


\section{Conflict of Interest}

R.B.L. is the Edwin S. Lowe Professor of Neurology at the Albert Einstein College of Medicine in New York. He receives research support from the NIH: 2PO1 AG003949 (mPI), 5U10 NS077308 (PI), RO1 NS082432 (Investigator), 1RF1 AG057531 (Site PI), RF1 AG054548 (Investigator), 1RO1 AG048642 (Investigator), R56 AG057548 (Investigator), K23 NS09610 (Mentor), K23AG049466 (Mentor), 1K01AG054700 (Mentor). He also receives support from the Migraine Research Foundation and the National Headache Foundation. He serves on the editorial board of Neurology, senior advisor to Headache, and associate editor to Cephalalgia. He has reviewed for the NIA and NINDS, holds stock options in eNeura Therapeutics and Biohaven Holdings; serves as consultant, advisory board member, or has received honoraria from: American Academy of Neurology, Alder, Allergan, American Headache Society, Amgen, Autonomic Technologies, Avanir, Biohaven, Biovision, Boston Scientific, Dr. Reddy's, Electrocore, Eli Lilly, eNeura Therapeutics, GlaxoSmithKline, Merck, Pernix, Pfizer, Supernus, Teva, Trigemina, Vector, Vedanta. He receives royalties from Wolff's Headache 7th and 8th Edition, Oxford Press University, 2009, Wiley and Informa. H.B. is on the Advisory Committee for Nutricia Australia; Clinincal Advisory Committee, Montefiore Home; Medical Advisory Committee, Cranbrook Care. N.S. reports personal fees from Merck Consumer Health and the NIH outside the submitted work. M.G. was on Biogen Inc.'s "Patient Journey Advisory Group” in 2016 and 2017. A.E.A. is a consultant for Kinsa Inc. and has received an unrestricted gift from Gojo Inc. H.B. is on the Advisory Board of Nutricia Australia.

\section{References}

1. Rawle MJ, Davis D, Bendayan R, Wong A, Kuh D, Richards M. Apolipoprotein-E (Apoe) $\varepsilon 4$ and cognitive decline over the adult life course. Transl Psychiatry. 2018;8(1):18. doi:10.1038/s41398-017-0064-8

2. Izaks GJ, Gansevoort RT, van der Knaap AM, Navis G, Dullaart RP, Slaets JP. The association of APOE genotype with cognitive function in persons aged 35 years or older. PLoS One. 2011;6(11):e27415. doi:10.1371/ journal.pone.0027415

3. Wisdom NM, Callahan JL, Hawkins KA. The effects of apolipoprotein E on non-impaired cognitive functioning: a meta-analysis. Neurobiol Aging. 2011;32(1):63-74. doi:10.1016/j.neurobiolaging.2009.02.003

4. Small B, Rosnick C, Fratiglioni L, Bäckman L. Apolipoprotein E and cognitive performance: a meta-analysis. Psychol Aging. 2004;19(4):592-600. doi:10.1037/0882-7974.19.4.592

5. Beydoun MA, Boueiz A, Abougergi MS, et al. Sex differences in the association of the apolipoprotein $\mathrm{E}$ epsilon 4 allele with incidence of dementia, cognitive impairment, and decline. Neurobiol Aging. 2012;33(4):720731.e4. doi:10.1016/j.neurobiolaging.2010.05.017

6. Caselli RJ, Reiman EM, Locke DE, et al. Cognitive domain decline in healthy apolipoprotein E epsilon4 homozygotes before the diagnosis of mild cognitive impairment. Arch Neurol. 2007;64(9):1306-1311. doi:10.1001/archneur.64.9.1306

7. Caselli RJ, Dueck AC, Osborne D, et al. Longitudinal growth modeling of cognitive aging and the APOE e4 effect. New Engl J Med. 2009;361(3):255-263. doi:10.1056/NEJMoa0809437

8. Caselli RJ, Dueck AC, Locke DE, et al. Longitudinal modeling of frontal cognition in APOE $\varepsilon 4$ homozygotes, heterozygotes, and noncarriers. Neurology. 2011;76(16):1383-1388. doi:10.1212/ WNL.0b013e3182167147

9. Caselli RJ, Reiman EM, Osborne D, et al. Longitudinal changes in cognition and behavior in asymptomatic carriers of the APOE e4 allele. Neurology. 2004;62(11):1990-1995. doi:10.1212/01.wnl.0000129533.26544.bf

10. Boyle PA, Buchman AS, Wilson RS, Kelly JF, Bennett DA. The APOE epsilon4 allele is associated with incident mild cognitive impairment among community-dwelling older persons. Neuroepidemiology. 2010;34(1):4349. doi:10.1159/000256662

11. Qian J, Wolters FJ, Beiser A, et al. APOE-related risk of mild cognitive impairment and dementia for prevention trials: an analysis of four cohorts. PLoS Med. 2017;14(3):e1002254. doi:10.1371/journal. pmed.1002254

12. Payami H, Zareparsi S, Montee KR, et al. Gender difference in apolipoprotein E-associated risk for familial Alzheimer disease: a possible clue to the higher incidence of Alzheimer disease in women. Am J Hum Genet. 1996;58(4):803-811.

13. Devanand DP, Pelton GH, Zamora D, et al. Predictive utility of apolipoprotein E genotype for Alzheimer disease in outpatients with mild cognitive impairment. Arch Neurol. 2005;62(6):975-980. doi:10.1001/ archneur.62.6.975

14. Mortensen EL, Høgh P. A gender difference in the association between APOE genotype and age-related cognitive decline. Neurology. 2001;57(1):89-95. doi:10.1212/wnl.57.1.89

15. Lehmann DJ, Refsum H, Nurk E, et al. Apolipoprotein E epsilon4 and impaired episodic memory in community-dwelling elderly people: a marked sex difference. The Hordaland Health Study. J Neurol Neurosurg Psychiatry. 2006;77(8):902-908. doi:10.1136/jnnp.2005.077818

16. Reinvang I, Winjevoll IL, Rootwelt H, Espeseth T. Working memory deficits in healthy APOE epsilon 4 carriers. Neuropsychologia. 2010;48(2):566573. doi:10.1016/j.neuropsychologia.2009.10.018

17. Fleisher A, Grundman M, Jack CR, Jr, et al. Sex, apolipoprotein e $\varepsilon 4$ status, and hippocampal volume in mild cognitive impairment. Arch. Neurol. 2005;62(6):953-957. doi:10.1001/archneur.62.6.953

18. Swan GE, Lessov-Schlaggar CN, Carmelli D, Schellenberg GD, La Rue A. Apolipoprotein E epsilon4 and change in cognitive functioning in community-dwelling older adults. J Geriatr Psychiatry Neurol. 2005;18(4):196-201. doi:10.1177/0891988705281864

19. Haan MN, Shemanski L, Jagust WJ, Manolio TA, Kuller L. The role of APOE epsilon4 in modulating effects of other risk factors for cognitive decline in elderly persons. JAMA. 1999;282(1):40-46. doi:10.1001/ jama.282.1.40

20. Liu CC, Liu CC, Kanekiyo T, Xu H, Bu G. Apolipoprotein E and Alzheimer disease: risk, mechanisms and therapy. Nat Rev Neurol. 2013;9(2):106118. doi:10.1038/nrneurol.2012.263

21. Llewellyn DJ, Lang IA, Matthews FE, et al. Vascular health, diabetes, APOE and dementia: the aging, demographics, and memory study. Alzheimers Res Ther. 2010;2(3):19. doi:10.1186/alzrt43

22. Peila R, Rodriguez BL, Launer LJ; Honolulu-Asia Aging Study. Type 2 diabetes, APOE gene, and the risk for dementia and related pathologies: the Honolulu-Asia aging study. Diabetes. 2002;51(4):1256-1262. doi:10.2337/diabetes.51.4.1256

23. Bender AR, Raz N. Age-related differences in memory and executive functions in healthy APOE $\varepsilon 4$ carriers: the contribution of individual differences in prefrontal volumes and systolic blood pressure. Neuropsychologia. 2012;50(5):704-14. doi:10.1016/j.neuropsychologia.2011.12.025

24. Farrer LA, Cupples LA, Haines JL, et al. Effects of age, sex, and ethnicity on the association between apolipoprotein $\mathrm{E}$ genotype and Alzheimer disease. A meta-analysis. APOE and Alzheimer disease meta analysis consortium. JAMA. 1997;278(16):1349-1356.

25. Crean S, Ward A, Mercaldi CJ, et al. Apolipoprotein E $\varepsilon 4$ prevalence in Alzheimer's disease patients varies across global populations: a systematic literature review and meta-analysis. Dement Geriatr Cogn Disord. 2011;31(1):20-30. doi:10.1159/000321984

26. Sachdev PS, Lipnicki DM, Kochan NA, et al.; COSMIC. COSMIC (Cohort Studies of Memory in an International Consortium): an international consortium to identify risk and protective factors and biomarkers of cognitive ageing and dementia in diverse ethnic and sociocultural groups. $B M C$ Neurol. 2013;13(1):165. doi:10.1186/1471-2377-13-165

27. Folstein MF, Folstein SE, McHugh PR. "Mini-mental state". A practical method for grading the cognitive state of patients for the clinician. $J$ Psychiatr Res. 1975;12(3):189-198. doi:10.1016/0022-3956(75)90026-6

28. Crane PK, Narasimhalu K, Gibbons LE, et al. Item response theory facilitated cocalibrating cognitive tests and reduced bias in estimated rates of decline. J Clin Epidemiol. 2008;61(10):1018-1027.e9. doi:10.1016/j. jclinepi.2007.11.011 
29. Thal LJ, Grundman M, Golden R. Alzheimer's disease: a correlational analysis of the blessed information-memory-concentration test and the mini-mental state exam. Neurology. 1986;36(2):262-264. doi:10.1212/ wnl.36.2.262

30. Griffith L, van den Heuvel E, Fortier I, et al. AHRQ Methods for Effective Health Care. Harmonization of Cognitive Measures in Individual Participant Data and Aggregate Data Meta-Analysis. Rockville, MD: Agency for Healthcare Research and Quality (US); 2013.

31. Gosho M. Model selection in the weighted generalized estimating equations for longitudinal data with dropout. Biom J. 2016;58(3):570-587. doi:10.1002/bimj.201400045

32. Salazar A, Ojeda B, Dueñas M, Fernández F, Failde I. Simple generalized estimating equations (GEEs) and weighted generalized estimating equations (WGEEs) in longitudinal studies with dropouts: guidelines and implementation in R. Stat Med. 2016;35(19):3424-3448. doi:10.1002/sim.6947

33. Thoemmes F, Ong AD. A primer on inverse probability of treatment weighting and marginal structural models. Emerging Adulthood. 2015;4(1):40-59. doi:10.1177/2167696815621645

34. Singer JB, Willet JB. Applied Longitudinal Data Analysis. New York: Oxford University Press; 2003.

35. IBM Corp. IBM SPSS Statistics for Windows, Version 23.0. Armonk, NY: IBM Corp.; 2015.

36. StataCorp. Stata Statistical Software: Release 13. College Station, TX: StataCorp LP; 2013.

37. Bonham LW, Geier EG, Fan CC, et al. Age-dependent effects of APOE $\varepsilon 4$ in preclinical Alzheimer's disease. Ann Clin Transl Neurol. 2016;3(9):668677. doi:10.1002/acn3.333

38. Corrada MM, Paganini-Hill A, Berlau DJ, Kawas CH. Apolipoprotein E genotype, dementia, and mortality in the oldest old: the 90+ study. Alzheimers Dement. 2013;9(1):12-18. doi:10.1016/j.jalz.2011.12.004

39. Small BJ, Rosnick CB, Fratiglioni L, Bäckman L. Apolipoprotein E and cognitive performance: a meta-analysis. Psychol Aging. 2004;19(4):592600. doi:10.1037/0882-7974.19.4.592

40. Tombaugh TN, McIntyre NJ. The mini-mental state examination: a comprehensive review. J Am Geriatr Soc. 1992;40(9):922-935. doi:10.1111/j.1532-5415.1992.tb01992.x

41. Sundermann EE, Maki PM, Rubin LH, Lipton RB, Landau S, Biegon A; Alzheimer's Disease Neuroimaging Initiative. Female advantage in verbal memory: evidence of sex-specific cognitive reserve. Neurology. 2016;87(18):1916-1924. doi:10.1212/ WNL.0000000000003288
42. Kalmijn S, Feskens EJ, Launer LJ, Kromhout D. Cerebrovascular disease, the apolipoprotein e4 allele, and cognitive decline in a community-based study of elderly men. Stroke. 1996;27(12):2230-2235. doi:10.1161/01.str.27.12.2230

43. Deschaintre Y, Richard F, Leys D, Pasquier F. Treatment of vascular risk factors is associated with slower decline in Alzheimer disease. Neurology. 2009;73(9):674-680. doi:10.1212/WNL.0b013e3181b59bf3

44. Crimmins EM, Hayward MD, Ueda H, Saito Y, Kim JK. Life with and without heart disease among women and men over 50.J Women Aging. 2008;20(1-2):5-19. doi:10.1300/j074v20n01_02

45. Stengård JH, Zerba KE, Pekkanen J, Ehnholm C, Nissinen A, Sing CF. Apolipoprotein E polymorphism predicts death from coronary heart disease in a longitudinal study of elderly Finnish men. Circulation. 1995;91(2):265-269. doi:10.1161/01.cir.91.2.265

46. Gromadzka G, Barańska-Gieruszczak M, Ciesielska A, SarzyńskaDlugosz I, Członkowska A. APOE genotype and serum cholesterol in predicting risk for early death from ischemic stroke in men and women. Cerebrovasc Dis. 2005;20(5):291-298. doi:10.1159/000087927

47. Walker KA, Power MC, Gottesman RF. Defining the relationship between hypertension, cognitive decline, and dementia: a review. Curr Hypertens Rep. 2017;19(3):24. doi:10.1007/s11906-017-0724-3

48. Emmerzaal TL, Kiliaan AJ, Gustafson DR. 2003-2013: a decade of body mass index, Alzheimer's disease, and dementia. J Alzheimers Dis. 2015;43(3):739-55. doi:10.3233/jad-141086

49. Mielke MM, Zandi PP, Sjögren M, et al. High total cholesterol levels in late life associated with a reduced risk of dementia. Neurology. 2005;64(10):1689-1695. doi:10.1212/01.WNL.0000161870.78572.A5

50. Park DC, Festini SB. The middle-aged brain: a cognitive neuroscience perspective. In: R. Cabeza, L. Nyberg, D. C. Park, editors. Cognitive Neuroscience of Aging: Linking Cognitive and Cerebral Aging. New York: Oxford University Press; 2014:363-388.

51. Jih J, Mukherjea A, Vittinghoff E, et al. Using appropriate body mass index cut points for overweight and obesity among Asian Americans. Prev Med. 2014;65:1-6. doi:10.1016/j.ypmed.2014.04.010

52. Liu X, Chen Y, Boucher NL, Rothberg AE. Prevalence and change of central obesity among US Asian adults: NHANES 2011-2014. BMC Public Health. 2017;17(1):678. doi:10.1186/s12889-017-4689-6

53. Gottesman RF, Schneider ALC, Zhou Y, et al. Association between midlife vascular risk factors and estimated brain amyloid depositionmidlife vascular risk factors and late-life brain amyloid depositionmidlife vascular risk factors and late-life brain amyloid deposition. JAMA. 2017;317(14):1443-1450. doi:10.1001/jama.2017.3090 